\title{
Regulative Principles and Kinds of the Unconditioned
}

\author{
ANGELA BREITENBACH \\ University of Cambridge \\ Email: ab335@cam.ac.uk
}

\begin{abstract}
In his Kant on Laws, Eric Watkins presents an account of reason on which the principles of specification and continuity are regulative instructions to search for different kinds of the unconditioned. I suggest that we correct Watkins' account in two ways. First, we need to complete Watkins' claim to the plurality of the unconditioned: reason aims for three kinds of the unconditioned, associated with the lowest, next and highest concepts. Second, we need to look beyond reason's search for the unconditioned in order to properly understand the nature of the aim of reason. I argue that we construe reason's aim as the systematic unity of cognition considered as a whole or, in Kant's teleological terms, as the realization of an 'idea', or a 'purposive unity'.
\end{abstract}

Keywords: reason, regulative principles, the unconditioned, systematic unity

Eric Watkins' Kant on Laws (Watkins 2019) is an impressive achievement. It carves out a precise but flexible account of Kant's conception of law and shows how this account is at play in a range of surprisingly diverse contexts: from the laws governing the starry heavens above me, to the moral law within me, via many other laws in between. In each of the twelve chapters, Watkins outlines a succinctly defined question, and answers it with the pleasing clarity distinctive of his work. Moreover, and beyond the insights revealed by the individual chapters, Watkins shows that there is an underlying unity to Kant's thinking about laws, and therefore - since laws play such a fundamental role in Kant's philosophy - to Kant's thinking as a whole. 
In my comments, I focus on some of the laws in between. I restrict myself, in particular, to comments on the regulative principles that Watkins discusses in part IV. In chapter ıo, 'Kant on Infima Species', he examines a set of prima facie metaphysical principles, the no lowest species and no next species claims that Kant puts forward in the Lectures on Logic. According to Watkins, the claims correspond to a set of regulative principles, the principles of specification and continuity, that Kant discusses in the Appendix to the Transcendental Dialectic of the Critique of Pure Reason. Watkins' account is insightful and has helped me make better sense of Kant's first Critique account of reason. It presents an account of reason on which the principles of specification and continuity are instructions, albeit merely regulative ones, to search for different kinds of the unconditioned. Watkins' account has also sharpened my understanding of where I disagree. I argue that Watkins overplays the continuity between the Lectures on Logic and the Appendix to the Transcendental Dialectic; and that he underplays the role of the third of the three regulative principles Kant discusses in the Appendix, the principle of homogeneity. I suggest that, as a result, we correct the picture that emerges from Watkins' discussion. I make two suggestions for correction. First, we need to complete Watkins' claim to the plurality of the unconditioned: reason aims for all three kinds of the unconditioned, associated with the lowest, next and highest concepts. Second, we ultimately need to look beyond reason's search for the unconditioned in order to properly understand the nature of the aim of reason. I suggest that we construe reason's aim as the systematic unity of cognition considered as a whole or, in Kant's teleological terms, as the realization of an 'idea', or a 'purposive unity'.

I begin, in section I, with a brief summary of the key claims and arguments Watkins puts forward in chapter IO. In section 2, I argue that his account sheds important light on Kant's conception of reason in the first Critique. But the insights gained also point to a difficulty with Watkins' reading, which I discuss in section 3. This leads me in section 4 to a suggestion for how to refocus a proper understanding of reason's aim.

\section{No Lowest and No Next Species and the Regulative Principles of Reason}

In chapter Io, Watkins targets two claims Kant puts forward in his Lectures on Logic (L-Log, 9: 97):

(i) There is no lowest species.

(ii) There is no next species. 
Watkins points out that these claims must be understood in the context of Kant's account of concepts and the systematic containment relations in which they stand to each other. As he shows, Kant follows the standard logic of his time in construing the system of concepts as systematically ordered according to their generality, with the most general concept at the top and increasingly more specific concepts ordered underneath. On this account, concepts of different generality stand in two kinds of containment relations, containment in and containment under. So, to use Watkins' example, 'the concept "living thing" contains the [more general] concepts "substance" and "living" in it and the [more specific] concepts "plant" and "animal" under it' (p. 213). What is distinctive about Kant's account, according to Watkins, is that the system of concepts has an important asymmetry: it has a highest concept, but no lowest and no next concepts.

Watkins shows that, on Kant's account, the system of concepts is headed by a highest concept because more general concepts are obtained by logical abstraction of content, and because there is a limit to such abstraction: at some point no further content can be abstracted from a concept without that concept disappearing. So, on Kant's account, there must be a most general concept at the top of the hierarchy of concepts, which contains all the more specific concepts under itself. As Watkins shows, Kant refers to this most general concept as 'the concept of something (24:9 I I), a thing (24: 755), or a possible thing (24: 259)' (p. 213).

Watkins furthermore argues that the system of concepts is not grounded in any lowest or next concepts, according to Kant, because more content can always be added to a concept, such that no concept is ever completely or fully determinate. In other words, for any species concept that falls under a higher genus concept, that species concept is further divisible into concepts of lower kinds. Moreover, for any two concepts that are related as genus and species, there is a further concept in between that contains the higher genus concept within it and the lower species concept under it. There is thus an infinity of divisions lower down as well as in between any given concepts in the hierarchy.

In chapter Io, Watkins asks why this last claim is true, if it is: why can more content always be added to a concept? What is Kant's justification for the anti-Leibnizian claim that we cannot have a completely determinate concept? And why should this be a matter of logic? To put it in terms of an example Watkins uses (p. 2I4), why should we be prepared to accept that there are infinitely many different beetle species, rather than 
350,000 , which is the current estimate? And why should we take an answer to this question from the logician, and not, say, the zoologist?

Watkins' key thesis is that Kant's answer is found in the Appendix to Transcendental Dialectic of the Critique of Pure Reason. There, Kant presents three principles of reason:

I. ... a principle of sameness of kind in the manifold under higher genera, 2. ... a principle of the variety of what is same in kind under lower species; and in order to complete the systematic unity ... 3. still another law of the affinity of all concepts, which offers a continuous transition from every species to every other through a graduated increase of varieties. We can call these the principles of the homogeneity, specification and continuity of forms. $(\mathrm{A} 657-8 / \mathrm{B} 685-6)^{\mathrm{I}}$

As Watkins argues, the three principles follow from Kant's conception of reason 'as the faculty that searches for the totality of conditions of what is conditioned and thus for the unconditioned' (p. 212). On Watkins' account, the search for higher, lower and intermediary concepts is the search for conditions (p. 22I). However, since the ultimate, unconditioned, condition is beyond our reach, the principles are purely regulative principles: they 'do not dictate what objects must be like, as strictly metaphysical principles would, but rather direct the understanding's activities in judgment' (p. 2I7).

Moreover, Watkins shows that the no lowest species and no next species claims correspond to two of the three regulative principles, namely, the principles of specification and continuity. Since the principles are merely regulative, reason's demand for a lowest and next species can never fully be discharged. The quest for a lowest or next species would be the demand for the unconditioned. And since the unconditioned is beyond our reach, any lowest or next species are as well. To show this, it is no use to investigate the phenomena. We must investigate reason, and thus hand over the reins to the logician, the transcendental logician, to be precise. In other words, Kant is the guy to go to if we are wondering about how many beetle kinds there are.

\section{Systematic Unity and the Unconditioned}

Watkins proposes to explain the no lowest and no next species claims Kant puts forward in the Lectures on Logic by situating them within the account of reason he presents in the Appendix to the 
Transcendental Dialectic. I find Watkins' discussion insightful and illuminating, specifically, with regard to Kant's first Critique account of reason, which provides the background to Watkins' discussion. I draw two particular insights from this reading.

First, Watkins clarifies the relation between two ways in which Kant characterizes reason in the first Critique. In the Appendix, Kant presents reason as searching for systematic unity among the cognitions of the understanding. It is this search that he construes as being guided by the three regulative principles of homogeneity, specification and continuity. As Watkins points out, Kant does not explicate how these principles relate to the search for conditions. By implication, he does not clarify either how his account of reason in the Appendix relates to his earlier characterization of reason, in the introductory sections of the Transcendental Dialectic, as the faculty that seeks conditions of cognitions and, ultimately, the unconditioned. Watkins' contribution is to clarify the connection between the search for systematic unity and the search for conditions and, thus, the relation between Kant's two characterizations of reason. According to Watkins, 'the crucial idea ... is that Kant views the containment relation that obtains between concepts of differing levels of generality as a kind of conditioning relation, one which reason, given its nature, must seek out' (pp. 219-20). As Watkins explains, in searching for lower or intermediary concepts, reason is searching for conditions. But the search for lower or intermediary concepts is what is demanded by the two regulative principles of specification and continuity, which in turn characterize reason's search for systematic unity. Watkins' interpretation thus shows that the search for conditions is expressed in the search for the systematic unity of cognitions.

Second, and more specifically, Watkins' discussion also brings to light the important pluralist dimension of reason's search for conditions. He shows that reason seeks different kinds of conditions, associated with the different regulative principles, in particular, the principles of specification and continuity. I find this insight especially enlightening because it offers a significant corrective to an account of reason one might read off the introductory sections of the Transcendental Dialectic. There, at the beginning of the Dialectic, Kant characterizes the inferences of reason from a given cognition to a more general principle as inferences to the condition of the cognition. He distinguishes 'the chain or series of prosyllogisms, i.e., of inferred cognitions on the side of the grounds, or of the conditions of a given cognition - in other words, the ascending series of syllogisms' from 'the descending series, i.e., the progression of reason on 
the side of that which is conditioned' $\left(\mathrm{A}_{33} \mathrm{I} / \mathrm{B}_{3} 88\right)$. Inferences to more and more general, or abstract, cognitions are inferences to the conditions, while inferences to more and more specific, or determinate, cognitions are inferences to the conditioned. The search for the unconditioned, in the early sections of the Dialectic, thus turns out to be the search for a most general principle.

Given this characterization of inferential conditioning relations, it would be natural to expect that Kant takes conceptual conditioning relations to run in the same direction. That is, it would be natural to expect Kant to locate conceptual conditions in more general, or more abstract, concepts, and the unconditioned in the most general, or most abstract, concept at the very top of the conceptual hierarchy. On such a reading, more general concepts would contain the conditions for more specific concepts because the more general concepts are contained in the more specific concepts. Let us call this 'containment-in conditioning'. For example, the more general concept 'metal' conditions the more specific concept 'copper', since 'metal' is contained in 'copper'.

Moreover, turning to the Appendix, it would then also be natural to expect the principle of homogeneity to have a certain privileged status vis-à-vis the principles of specification and continuity. One might be tempted to give the principle of homogeneity priority over the principles of specification and continuity because one might associate the systematic unity of cognition with only one kind of unconditioned, namely, the unconditioned in the form of the most general concept. And it is this kind of unconditioned that is associated with the principle of homogeneity. One might thus associate the systematic unity of cognition with homogeneity, that is, with the unity of a manifold of cognitions under a highest concept.

I take Watkins' account to show that such a reading would be wrong. Kant does not identify the search for the systematic unity of cognition with the search for only one kind of condition, and one kind of unconditioned. For Kant, the systematic unity of cognitions consists in the search for a plurality of conditions. More specifically, Watkins takes at least one type of conditioning relation in the system of concepts to run the other way. Indeed, Watkins' primary focus seems to be on conditioning relations going from the more specific to the more general concepts. ${ }^{2} \mathrm{Or}$, as he puts it, 'if one concept contains another in itself, then the content of the one conditions that of the other' (p. 220). If I understand him correctly, more specific concepts condition more general concepts 
insofar as they are contained under the latter. To come back to my earlier example, the concept 'metal' conditions the more general concept 'substance' since 'metal' is contained under the concept 'substance'. Let us call this second kind of conditioning relation 'containment-under conditioning'.

Moreover, since Watkins thinks Kant is a pluralist about conditioning relations (p. 220), he takes Kant to allow for different kinds of conditioning relations running in different directions. In particular, he argues that Kant makes room for the conditions to be found in more general and more specific concepts in his comments on the no next species claim (p. 22I). On Watkins' account it thus follows that reason's search for the systematic unity of cognitions is characterized, not by the search for ever more general containment-in conditions, and ultimately a containment-in unconditioned, but by the search for a plurality of distinct kinds of conditions and, ultimately, a plurality of distinct kinds of unconditioned.

\section{No Highest Genus and the Principle of Homogeneity}

The insights I have highlighted also point to a problem I see with Watkins' proposal. Watkins avoids the mistake of putting too much emphasis on the principle of homogeneity. But he thereby commits another, namely, paying too little attention to the principle of homogeneity. In part, this lack of attention is justified by the aim of the chapter. Chapter Io is, after all, concerned to explain the no lowest species and no next species claims. But the problem I want to point to can be rephrased in terms that fall more explicitly within the remit of the chapter. Thus, Watkins shows convincingly that the no lowest species and no next species claims correspond to the search for the unconditioned maxims expressed in the principles of specification and continuity. But given this correspondence, one would expect Kant to align the third principle of reason, the principle of homogeneity, with a third claim, namely, a no highest species claim. In other words, one would expect the system of concepts to have not only no bottom and no middle, but also no top. Why, then, does Watkins affirm that there is a highest genus concept at the top of the conceptual hierarchy?

Let us consider the three regulative principles one by one. First, on Watkins' account, there is no lowest concept in the conceptual hierarchy. I would describe the reason thus: the understanding cannot satisfy reason's demand for the unconditioned, in this case, a complete concept that contains all the containment-under conditions. Reason forms the idea of 
complete specificity. But the understanding deals in general concepts. It cannot produce the fully determinate concept reason demands. This is why there can be no lowest concept.

Second, according to Watkins, there is no next concept in the conceptual hierarchy for analogous reasons. Watkins does not spell these reasons out in detail but, if I understand him correctly, they amount to the following. Reason asks for the conditions of concepts. But these conditions need not lie in ever more specific concepts; they can also lie in between two given concepts, and therefore also in more general concepts. Reason is after all conditions. It thus forms the idea of the unconditioned in the form of the complete continuity of all conditioning concepts. But the understanding deals in general concepts. It cannot satisfy reason's demand for concepts that completely specify such continuity. This is why there can be no next concept.

Third, according to Watkins, Kant explicitly maintains that there is a highest concept in the conceptual hierarchy. This is the important asymmetry of the system of concepts that Watkins detects in the Lectures on Logic and that, if I read him correctly, he also takes to be at work in the Appendix. The picture that thus emerges from his account is one in which the principle of homogeneity demands the search for ever more general concepts up to this highest concept: it consists in the search for 'a series of increasingly higher, or more universal, concepts, up to the highest concept of all' (p. 216). On Watkins' account, while the conceptual hierarchy cannot have a lowest or next concept, it can, and in fact does, have a highest concept.

I find this asymmetrical account of the system of concepts convincing as a reading of Kant's claims in the Lectures on Logic. There, Kant is concerned with the logical containment relations between concepts, that are characterized by abstraction or determination. ${ }^{3}$ But I find Watkins' account unconvincing as a reading of the Appendix. In the Appendix, Kant is concerned with a particular set of concepts, namely, possible empirical concepts provided by the understanding, and their systematic relations. As Kant puts it in the Appendix, the use of reason and its ideas is 'immanent' 'in regard to the whole of possible experience' (A643/B67I). By contrast, the 'concept of something (24:9II), a thing (24: 755), or a possible thing (24:259)' (p. 2I3) has no empirical content. It is an a priori concept that, just like the categories, may inform each empirical concept within the hierarchy, but is not itself a node in the hierarchy. 
Moreover, on my reading, the reason why there can be no highest empirical concept is closely related to why there can be no lowest or next concepts. In order to determine the most general empirical concept, we would need to determine all the more specific empirical concepts ordered beneath. We would need to rule out that there are any other empirical concepts that do not fall under the highest empirical concept. But this demand of reason for a complete determination of the system of concepts cannot be satisfied by the understanding. We therefore cannot have the highest concept of the empirical conceptual hierarchy. We can have a highest logical concept, that is, the concept of 'a thing' or 'a possible thing', but we cannot have a highest empirical concept. Just like the lowest or next species, the highest genus would be a form of the unconditioned. There is no asymmetry in the system of empirical concepts.

I believe this conclusion makes better sense of Kant's account of the regulative principles in the Appendix, and also of Watkins' core idea that conceptual containment relations are a form of conditioning relations. If the principle of homogeneity follows from reason's search for the unconditioned, as Watkins argues it does, one should expect that, in following it, the activities of the understanding could never terminate in a highest concept. If, by contrast, the highest concept that the principle of homogeneity asked us to seek were a concept we already possessed, it would be unclear how the principle of homogeneity could have the status of a regulative principle of reason. There would be no way in which it could fail to lead us to a highest concept. It would be unclear why the principle of homogeneity is a regulative and not a constitutive principle. And if, moreover, the principle of homogeneity really asked us to search for ever higher concepts $u p$ to a highest concept we already possess, as seems to be implied by Watkins' reading (p. 216), it would be unclear why it does not reduce to the principle of continuity. We would need an account of why Kant needed the principle of homogeneity as a distinct addition to his triad of the regulative principles of reason.

On my reading, the three regulative principles thus instruct us to search for ever higher, lower and intermediary concepts. But the highest, lowest and next concepts would be forms of the unconditioned. They are mere ideas. That is why, in the Appendix, Kant is warranted to assert not only that there are no absolutely lowest or next species but also the claim that there is no absolutely highest genus: or, in other words, that the highest genus is 'a mere idea' (A652/B680). 
I thus propose that Watkins' pluralist account of the unconditioned needs to be corrected to involve all kinds of the unconditioned, including those associated with the highest, lowest and next concepts. Only by following all three regulative principles of reason, can we get a full account of the kinds of unconditioned that reason seeks in aiming for the systematic unity of cognition.

\section{Beyond the Unconditioned}

I have proposed to correct Watkins' account by construing reason's search for systematic unity as involving the search for three kinds of unconditioned. Given this pluralism of the unconditioned, one might wonder what remains of the demand for unity that Kant associates with reason. Does not the search for different kinds of unconditioned pull us in different directions? And is the unity that reason is after not more unified than that? I believe that, in order to answer these questions, we ultimately need to focus less on the search for the unconditioned, and more on reason's search for systematic unity - or as Watkins puts it at one point in the chapter, on reason's 'single interest (in cognizing the totality of conditions in a systematic whole)' (p. 22 I; my italics). I thus suggest there is a reason why in the Appendix Kant shifts his focus from reason's search for the unconditioned to that of systematic unity: getting a proper grasp of reason's idea of unity is what ultimately gives us insight into the aim and function of reason. It is this idea of unity that, as Kant puts it in the Appendix, grounds 'the possibility of the greatest use of human reason' (A694-5/B722-3).

Focusing on the different kinds of conditioning relations is thus useful for understanding the different ways in which reason seeks the systematic unity of cognition. But exploring only this search for conditions and the unconditioned sheds inconclusive light on the character of the unity reason thereby seeks. Thus, Kant suggests that the unity of cognitions that we aim for by searching for all forms of conditions is a unity that takes all conditions together as a totality. In searching for systematic unity, reason is not primarily after any one node in the system - not even the highest but after the entire system taken as a whole. I think that we cannot make sense of this entirety as a mere extension of the hierarchical model of the system of concepts that we have been working with so far. By contrast, I suggest that Kant ultimately makes sense of this whole in teleological terms, as a unity that is made or brought about as the realization of an 'idea' (A645/B673), and thus as a 'purposive unity' (A686/B714). ${ }^{4}$ It is the idea of this 'highest' (A686/B7I4) unity that, Kant thinks, 'is inseparably bound up with the essence of our reason' (A694-5/B $722-3$ ). 


\section{Notes}

I Translations are from Kant 1999.

2 Watkins cites Kant's reference to ' $I$ ) the concept as condition, 2) the conditioned, and 3 ) the derivation of the latter from the former' in support of this reading of conceptual conditioning ( $L-L o g$, 9: I48; see also CPJ, 5: I97 and Refl-Log, I6: 623). I agree with Watkins that this is textual evidence for the claim that Kant regards concepts as conditions. But I take this passage to be neutral on the question of the direction of conditioning. It leaves room for either containment-in or containment-under conditioning.

3 This asymmetry raises the further question of why, in the Lectures on Logic, Kant does not allow for the purely logical notion of a complete concept, and thus for the possibility of a lowest or next concept. This is a question I cannot deal with here.

4 I spell this idea out in more detail in Breitenbach (forthcoming). Willaschek comments on the difference between the hierarchical and holistic conceptions of unity in his (20I8: $53-5)$.

\section{References}

Breitenbach, Angela (forthcoming) 'The Regulative Role of Reason'. In A. Gomes and A. Stephenson (eds), Oxford Kant Handbook (Oxford: Oxford University Press).

Kant, Immanuel (1999) Critique of Pure Reason. Trans. and ed. P. Guyer and A. W. Wood. Cambridge: Cambridge University Press.

Watkins, Eric (2019) Kant on Laws. Cambridge: Cambridge University Press.

Willaschek, Marcus (2018) Kant on the Sources of Metaphysics. Cambridge: Cambridge University Press. 